\title{
A construção da Identidade, Auto-conceito e Autonomia em Adultos Emergentes
}

\author{
Cláudia Andrade \\ Escola Superior de Educação de Coimbra - Instituto Politécnico de Coimbra - Portugal
}

\section{Resumo}

A adultez emergente implica a resolução de algumas tarefas desenvolvimentais clássicas para se poder construir, progressivamente, um projeto pessoal, num quadro de autonomia psicológica e social. A construção da identidade e o desenvolvimento do auto-conceito vão integrar vivências pessoais e prolongam-se além desta fase desenvolvimental, dando sentido ao percurso de vida do indivíduo. No presente estudo procuramos explorar o modo como o exercício de uma atividade profissional pode influenciar a construção da identidade, o auto-conceito e a separação psicológica das figuras parentais em adultos emergentes que estudam no ensino superior e adultos emergentes que já exercem uma atividade profissional. O estudo comparou 361 adultos emergentes universitários e 348 adultos emergentes profissionais. Os resultados encontrados suportam a presença de diferenças entre grupos nas três dimensões desenvolvimentais escolhidas para o estudo.

Palavras-chave: Identidade; autoconceito, autonomia.

\section{Identity construction, Self-concept and Autonomy in Emerging Adults}

\begin{abstract}
Emerging adulthood involves the resolution of some classic developmental tasks in order to gradually build a personal project in a framework of psychological and social autonomy. The construction of identity and the development of self- concept will integrate personal experiences and it extends beyond this developmental stage, giving meaning to one's life path. In the present study we aimed to explore how having a professional activity can influence the construction of identity, self-concept and psychological separation of parental figures, in emerging adults who study in higher education and emerging adults who have a professional occupation. The study compared 361 emerging adults (college students) and 348 emerging adults (with an academic degree and having a regular professional occupation). The results supported the existence of differences between the two groups in the three developmental dimensions selected for the study.
\end{abstract}

Key-words: Identity construction; self-concept; autonomy.

\section{La construcción de la Identidad, Auto-concepto y Autonomía en Adultos Emergentes}

\section{Resumen}

La adultez emergente implica la resolución de algunas tareas desarrolladas clásicas para poder construirse, progresivamente, un proyecto personal, en un cuadro de autonomía psicológica y social. La construcción de la identidad y el desarrollo del auto-concepto van a integrar vivencias personales y se alarguen más allá de esta fase del desarrollo, dando sentido a la trayectoria de vida del individuo. El presente estudio busca explorar el modo como el ejercicio de una actividad profesional puede influenciar la construcción de la identidad, el auto-concepto y la separación psicológica de las figuras parentales en adultos emergentes que estudian en la enseñanza superior y adultos emergentes que ya ejercen una actividad profesional. El estudio comparó 361 adultos emergentes universitarios y 348 adultos emergentes profesionales. Los resultados encontrados soportan la presencia de diferencias entre grupos en las tres dimensiones desarrollos escogidas para el estudio.

Palabras clave: Identidad; auto-concepto; autonomía. 


\section{Introdução}

$\mathrm{Na}$ adultez emergente ocorre um conjunto de alterações ao nível psicológico traduzidas no desenvolvimento, realização e consolidação da identidade pessoal e social do sujeito que culminarão com a aquisição do estatuto social de adulto (Andrade, 2010a). Assim, a vivência da adultez emergente implica a resolução de algumas tarefas desenvolvimentais clássicas para se poder construir, progressivamente, um projeto pessoal, num quadro de autonomia psicológica e social. A construção da identidade e o desenvolvimento do auto-conceito vão integrar vivências pessoais e prolongam-se além desta fase desenvolvimental, dando sentido ao percurso de vida do indivíduo. Assim, na adultez emergente vão-se construir valores e atitudes próprias assumindo-se, progressivamente, comportamentos sem senecessitar, constantemente, do apoio emocional e instrumental dos pais (Andrade, 2010a; Mendonça, Andrade, \& Fontaine, 2009). Este processo, designado por "separação psicológica das figuras parentais", aparece associado à conquista da autonomia por parte do adulto emergente, que Ihe conferirá uma melhor capacidade de adaptação às exigências sociais do futuro papel de adulto. De acordo com Côté e Schwartz(2002) e Tanner (2006), o comportamento regulado pelos outros passa a ser regulado pelo próprio, o que se opera de acordo com dois processos desenvolvimentais: o processo de separação-individuação e a construção da identidade.

\section{A Construção da Identidade}

O conceito de identidade tem sido alvo de alguma controvérsia na sua definição conceptual, dado que, como refere Costa (1991) "os termos identidade, self, caráter e personalidade têm sido usados para definir a unicidade que diferencia o indivíduo dos outros; uma distinção clara entre os termos é, no entanto, difícil de estabelecer" (p.20). Todavia, apesar destas dificuldades, tem havido uma preocupação dos diferentes autores em clarificar e compreender o processo de construção da identidade, procurando a identificação dos acontecimentos, etapas e elementos que intervêm, com maior relevo, neste processo. Como refere Costa (1991), Erikson é consagrado, na literatura psicológica, como o primeiro autor a analisar em profundidade o fenómeno da identidade, tanto ao nível conceptual como ao nível da sua formação e desenvolvimento. Em 1968, definiu a identidade de uma forma integrada, em que a dimensão biológica, a vivência pessoal das experiências e o meio cultural dão sentido aos percursos do indivíduo. Baseando-se na perspetiva de Erikson, Marcia $(1966,1986)$ procurou identificar quais os critérios psicossociais associados à aquisição da identidade. O autor aponta para a existência de quatro estatutos de identidade, que representam diferentes estilos de lidar com esta tarefa psicossocial e que são definidos pela presença ou ausência de exploração e de investimento em áreas específicas: profissional, ideológica (religiosa e polí- tica), interpessoal/sexual (atitudes sobre os papéis sexuais e sobre a participação em relações sexuais) (Costa, 1991).

Por exploração entende-se o questionamento sistemático na tomada de decisões e alcance de objectivos, onde se desenvolvem atividades prévias de recolha de informação, fundamentais para este processo. Refere também a existência de três modalidades relativamente à atividade de exploração: a ausência de exploração, durante a exploração, após a exploração. Para diferenciar estes momentos, o autor indica que na ausência de exploração, o indivíduo não sente necessidade de escolher alternativas nem de tomar decisões, quer porque já estão definidos por outrem, quer porque foram aceites sem questionamento; o indivíduo está em exploração quando sente necessidade de questionar e reflectir sobre as dimensões referentes à sua identidade, com o objetivo de tomar decisões. Para tal, analisa as várias opções, tomando progressiva consciência do conteúdo e implicações de cada uma delas. Após a exploração, o indivíduo integra a identidade, apresentando um sentido de direção para o futuro, ou seja, projetando-se num conjunto de papéis sociais que tenciona vir a desempenhar. $\mathrm{O}$ investimento implica, por um lado, opções e escolhas relativas ao futuro e, por outro lado, a sua tradução em comportamentos que conduzem potencialmente à sua concretização. $\mathrm{O}$ investimento carateriza-se não só pela capacidade de enunciar valores e atitudes socialmente apropriados, como pela sua manifesta influência nos projetos de vida do indivíduo, originando um sentido de continuidade entre o passado, o presente e o futuro.

Partindo destes dois construtos (exploração e investimento), Marcia define quatro estilos que os indivíduos podem assumir perante a tarefa da identidade, sendo que cada um deles é definido pela presença ou ausência de períodos de exploração e de investimento nas áreas específicas acima referidas. Estes estilos são designados por estatutos de identidade: identidade construída, moratória, vicariante e difusão.

$\mathrm{O}$ estatuto de identidade construída surge quando o indivíduo passou por um período de exploração e realizou investimentos que lhe permitem apresentar uma identidade consolidada. O estatuto de identidade moratória surge em sequência de uma vivência atual de exploração ativa das alternativas para a posterior tomada de decisões. $\mathrm{O}$ estatuto de identidade vicariante surge quando não há indícios de existência de nenhum período de exploração anterior ou atual, mas existe, contudo, um investimento que, normalmente, é fruto de escolhas e projetos de outras figuras significativas ou de autoridade. $O$ estatuto de identidade difusão surge quando o indivíduo não tem, nem pretende ter, qualquer investimento, nem passou por qualquer período de exploração prévia, levando a que as questões desenvolvimentais que foram levantadas não sejam resolvidas ou tenham sido abandonadas. Esta classificação refere-se a formas de resolução de tarefa de construção da identidade (Costa, 1991).

Deste modo, e apesar da adultez emergente se constituir como uma etapa do ciclo vital, determinante para a consolidação da identidade, a diversidade de experiências pessoais, assim como a variabilidade dos contextos sociais em que os adultos emergentes se inserem, explicam 
a existência de diferentes estatutos de identidade, mesmo em classes etárias semelhantes. A identidade difusão, geralmente considerada como o estatuto mais imaturo e, como tal, menos complexo, reflete-se numa apatia e ausência de reflexão acerca do futuro, onde os compromissos não são estáveis ou não se mantém a longo prazo. Ora, para Coté (1996), este tipo de identidade é muito caraterístico das sociedades atuais, onde nada é definitivo e tudo parece muito mutável. Também o é a identidade moratória, que implica uma ausência de compromissos, apesar de ser um estatuto mais complexo, na medida em que o indivíduo se questiona e assume uma certa pró-atividade na busca da sua autonomia e na exploração de diversas opções para o seu futuro. É um estatuto que pode encerrar, em si mesmo, níveis elevados de ansiedade e incerteza (Côté \& Swartz, 2002).

Nesta perspetiva, os estatutos de identidades difusão e moratória têm muito em comum e podem ser "funcionalmente adaptativos", num mundo que está em mutação. A identidade construída é considerada como a que revela um maior grau de maturidade, já que os compromissos foram estabelecidos pelo próprio. Implica que o indivíduo seja capaz de estabelecer relacionamentos interpessoais maduros, por exemplo com os pais, e que seja capaz de pensar na sua vida, tendo em consideração diversos papéis (Côté \& Swartz, 2002). Também a identidade vicariante permite a construção de planos em relação à vida adulta, tomando como referência clara os modelos sociais, nomeadamente os modelos parentais, com o objectivo de serem reproduzidos em termos futuros.

\section{O desenvolvimento do Auto-Conceito}

Se a identidade representa o self enquanto sujeito, o auto-conceito pode ser definido como um conjunto de pensamentos e sentimentos que se referem ao self enquanto objeto, sendo formado a partir das experiências e das interpretações que efetuam do ambiente que os rodeia, ou seja, permite percecionarem-se como indivíduos dotados de atitudes, valores e comportamentos (Adamson \& Lyxel, 1996; Shavelson, Hubner, \& Stanton, 1976). Será, contudo, importante clarificar que o auto-conceito não constitui necessariamente uma visão "objetiva" do que cada um é, sendo reflexo do modo como nos percecionamos a nós próprios. Para Shavelson e cols. (1976), o auto-conceito não é uma entidade em si mesma. É um construto hipotético, que é particularmente útil ao nível da predição dos comportamentos enquanto variável mediadora para a explicação dos comportamentos dos indivíduos. Apesar da sua natureza de construto hipotético, constitui-se como uma unidade de coerência do comportamento individual, dando ao indivíduo a noção de continuidade e de identidade no tempo e atuando como regulador da vida pessoal (Yount, 1986).

O desenvolvimento do auto-conceito, segundo Rosenberg e Simmons (1975), efetua-se de acordo com processos específicos. Depende das avaliações refletidas, quando o indivíduo se vê a si próprio de acordo com o modo como pensa que os outros o vêem: a comparação social, na medida em que o indivíduo se vê por comparação com outros considerados significativos; as auto-atribuições, dado que a descrição que o indivíduo faz de si mesmo resulta da interpretação das causas de acontecimentos pessoais, que resultam ou não das suas ações. Esta abordagem destaca a importância das relações sociais para a formação do autoconceito já que Rosenberg e Simmons (1975) salientam que, mesmo as auto-atribuições que parecem estar centradas na estrutura psicológica de cada indivíduo, são produtos sociais, dado que só podem ser construídas a partir de contextos sociais de referência.

O auto-conceito é, deste modo, considerado como um sistema de crenças, multidimensional e dinâmico, onde o desenvolvimento das diferentes dimensões pode seguir diferentes padrões ou trajetórias, desde a infância até a idade adulta. A maioria das perspetivas sobre o desenvolvimento do auto-conceito assume, contudo, que este se vai tornando progressivamente mais estável ao longo do processo de desenvolvimento (Cole \& cols., 2001). Ao nível do desempenho de papéis sociais, Harter (1983) indica que as diferentes áreas da vida podem assumir mais ou menos importância na definição do auto-conceito e que esta importância relativa varia com a idade. No adulto, a competência profissional, a sociabilidade e as relações de amizade e familiares ocupam um lugar central (Harter, 1983). Assim, importa avaliar no adulto os julgamentos de competência de forma autónoma, em cada um destes domínios.

Para a autora, as competências do indivíduo, reconhecidas pelo próprio em relação a uma determinada aptidão num domínio específico da sua vida, associam-se intimamente ao seu sentido de valor pessoal nesse domínio e ao fato do indivíduo se considerar competente em domínios que considera relevantes para a sua vida. Contudo, este julgamento de competências é influenciado não só pela apreciação da aptidão específica, como pela importância que o domínio tem para o indivíduo. Nesta situação particular, o indivíduo tende usualmente a desenvolver estratégias protetoras, em que se mostra propenso a atribuir a si a maior responsabilidade pelos êxitos do que pelos fracassos (Harter, 1983). Ao proceder deste modo, continua a preservar o sentido do seu valor pessoal, independentemente dos resultados das circunstâncias em que está envolvido. $\mathrm{Na}$ medida em que as diferentes experiências e contextos de desenvolvimento podem determinar diferenças na formação destes dois construtos, é previsível que a sua construção varie em função do género.

\section{A Separação Psicológica das Figuras Parentais}

A conquista da autonomia constitui-se como outra tarefa desenvolvimental fundamental na transição para a idade adulta. Exige a separação psicológica das figuras parentais que ocorre, segundo Blos (1979), ao longo do processo de separação-individuação, durante a passagem da adolescência para a idade adulta. É, progressivamente, que 
se processa a separação dos objetos infantis internalizados e que se adquire uma maior independência/autonomia em relação aos pais (Blos, 1979). De acordo com esta perspetiva, a separação psicológica das figuras parentais é uma condição para a construção da autonomia por parte do jovem. De um modo geral, aparece associada a uma melhor capacidade de adaptação em relação às exigências sociais, já que o desenvolvimento da autonomia permite que este se afirme ao nível do desempenho do seu papel de adulto.

Baseando-se na Teoria de Blos, Hoffman (1984) descreve o processo de separação psicológica das figuras parentais de acordo com quatro dimensões: a autonomia funcional, que se carateriza pela capacidade do adolescente ou jovem adulto tratar dos seus próprios assuntos sem a ajuda do pai ou da mãe; a autonomia ideológica, que corresponde ao grau de diferenciação entre o adolescente ou jovem adulto e os seus pais no domínio dos valores, crenças e atitudes; a autonomia emocional, que é definida como uma relativa liberdade do adolescente ou jovem adulto em relação à necessidade excessiva de aprovação, proximidade e apoio emocional por parte dos pais; e, por último, a autonomia conflitual, definida como liberdade em relação a uma culpa excessiva, ansiedade, responsabilidade, inibição, ressentimento e raiva em relação ao pai e à mãe (Dias, 1996).

A concetualização teórica de Hoffman foi também analisada ao nível empírico, com resultados bastante abonatórios do modelo. As diversas investigações, utilizando o instrumento de avaliação psicológica desenvolvido por Hoffman (1984), sugerem que a ansiedade, associada às emoções negativas de zanga, ressentimento, conflito, relativas à separação, ou seja, a falta de independência conflitual, têm uma importância maior para a adaptação global dos jovens aos diferentes contextos sociaisdo que as outras formas de independência, nomeadamente, funcional, emocional e ideológica (Hoffman, 1984). Assim, as dificuldades ao nível da aquisição da independência conflitual parecem traduzir-se em dificuldades de inserção social dos jovens, levando à emergência de sentimentos de insegurança e de falta de autonomia em geral.

Outros estudos corroboraram ainda esta perspetiva, na medida em que a ausência de sentimentos de ansiedade relacionados com a separação psicológica das figuras parentais aparece associada à resolução, com sucesso, de várias tarefas de desenvolvimento psicológico dos jovens, tais como a realização profissional, o estabelecimento bem sucedido de relações extra-familiares e ainda um generalizado sentimento de bem-estar (Leondari \& Kiosseoglou, 2000).

Em suma, a separação psicológica das figuras parentais, a par da construção da identidade e da formação do auto-conceitosurgem, na adultez emergente, enquanto tarefas fundamentais para a conquista da autonomia e posterior obtenção do estatuto social de adulto.

A construção da identidade pessoal e social do adulto emergente, que se legitima através do exercício de papéis sociais de adulto como, por exemplo, o papel profissional pode contribuir para que este haja, sem necessitar constantemente do apoio emocional e instrumental por parte dos pais. Do mesmo modo, também aconstrução da identidade e do auto-conceito envolvem, de uma forma integrada, aspetos que se reportam a essas vivências pessoais nas quais a entrada no mercado de trabalho pode desempenhar um papel determinante. No presente estudo procuramos explorar o modo como o exercício de uma atividade profissional pode influenciar a construção da identidade, o auto-conceito e a separação psicológica das figuras parentais em adultos emergentes que estudam no ensino superior e adultos emergentes que já exercem uma atividade profissional. Assim, formulamos um conjunto de hipóteses diferenciais que passamos a apresentar.

Hipótese 1: Os adultos emergentes estudantes apresentam valores mais elevados nos estatutos de identidade vicariante e moratória/difusão, enquanto que os adultos emergentes trabalhadores apresentam valores mais elevados na identidade construída $(\mathrm{H} 1)$.

Hipótese 2: Os adultos emergentes estudantes apresentam valores mais elevados no auto-conceito geral e de competência profissional do que os adultos emergentes trabalhadores. Não haverá diferenças entre grupos no auto-conceito relativo ao cuidar dos outros e à gestão das tarefas domésticas $(\mathrm{H} 2)$.

Hipótese 3: Os adultos emergentes estudantes universitários apresentam valores mais baixos do que os trabaIhadores na independência conflitual, ideológica, emocional e funcional $(\mathrm{H} 3)$.

\section{Método}

\section{Participantes}

O estudo empírico incide sobre 361 adultos emergentes a frequentar o ensino superior (de Universidades e Institutos Superiores da região do grande Porto) e 348 adultos emergentes com diploma universitário e a exercer uma atividade profissional a tempo inteiro (provenientes na grande maioria dos casos da região do grande Porto e em alguns casos da região centro do país). A maioria dos adultos emergentes universitários e alguns adultos emergentes trabalhadores foram contactados em instituições de ensino universitário. Os restantes adultos emergentes universitários, bem como a maioria dos adultos emergentes trabalhadores, foram contactados individualmente ou em pequenos grupos, em diferentes locais, com especial predomínio pelos locais de trabalho. As idades para ambos os grupos estiveram compreendidas entre os 18 e os 29 anos. A idade média foi de 21.05 anos com um desvio-padrão de 3.45 para os estudantes e de 27.09 com um desvio-padrão de 3.09 para os trabalhadores. A distribuição por sexos apresentou $68 \%$ de sujeitos do sexo feminino e $32 \%$ do sexo masculino. Tanto os estudantes como os trabalhadores vivem preferencialmente em casa dos pais, $73 \%$ e $62 \%$, respetivamente. Os restantes vivem ou com amigos ou com colegas, $27 \%$ para os estudantes e $36 \%$ para trabalhadores, e apenas $2 \%$ dos trabalhadores vivem com o parceiro/namorado. 


\section{Instrumentos}

Para avaliar as dimensões da autonomia foi escoIhido o Inventário de separação psicológica das figuras parentais, Psychological Separation Inventory, de Hoffman (1984) no qual a separação psicológica em relação aos pais é avaliada através de quatro escalas de independência, respetivamente independência funcional, emocional, ideológica e conflitual, sendo a separação em relação ao pai e à mãe consideradas independentemente, dadas as suas implicações distintas na adaptação pessoal do jovem. Na sua forma final o Psychological Separation Inventory compreende um total de 138 questões, 69 correspondentes ao pai e 69 correspondentes à mãe, com um formato de resposta tipo Likert, numa escala de cinco níveis. Hoffman (1984) levou a cabo estudos de validação deste inventário que permitiram, por um lado, concluir sobre a validade deste instrumento, assim como relacionar os vários tipos de independência com outras variáveis psicológicas (como o bem-estar psicológico, o tipo de relações familiares, os problemas dos estudantes universitários e ainda sua adaptação à universidade) e variáveis do desenvolvimento diferencial (como o sexo e a idade).

A versão portuguesa do inventário foi testada numa população de universitários (Dias, 1996) e apresentou uma estrutura em quatro fatores que correspondem às quatro dimensões teóricas tanto para os dados relativos à mãe (que explicaram $38.4 \%$ da variância total) como para os dados relativos ao pai (que explicaram $41.9 \%$ da variância total). Todas as sub-escalas ficaram constituídas por 11 itens com bons índices de consistência interna (>.80). Sendo uma escala adaptada para uma população universitáriaPortuguesa e que apresenta boas qualidades psicométricas considerou-se adequada para os propósitos deste estudo.

\section{Estatutos de Identidade}

Para a avaliação dos estatutos de identidade neste estudo optou-se por fazer recurso ao EOMEIS-2 - Extended Version of the Objective Measure of Ego Identidade Status na sua versão portuguesa (Matos, Barbosa, Almeida, \& Costa, 1999). Este instrumento foi adaptado para a população portuguesa por Matos e cols. (1999) sendo constituído por 64 itens, organizados nos quatro estatutos de identidade definidos por Marcia: identidade construída, identidade moratória, identidade vicariante e identidade difusa onde as alternativas de resposta se situam ao longo de uma escala de Likert de 6 pontos (de concordo fortemente a discordo fortemente). A fiabilidade do instrumento foi analisada pelas autoras a partir das dimensões originais do EOMEIS-2 numa amostra portuguesa de 530 jovens tendo os valores de alfa de Cronbach variam entre .54 e .71. Estes valores de consistência interna apesar de serem fracos são, na sua maioria, aceitáveis para a comparação de grupos.

\section{Auto-Conceito}

Para avaliar o auto-conceito recorreu-se ao Adult Self-Perception Profile desenvolvido por Messer \& Harter (1986) dado tratar-se de um instrumento que efetua uma abordagem diferenciada das componentes do sentido de competência dos adultos. De fato, apesar do auto-conceito ser reconhecidamente um constructo multidimensional os instrumentos de medida encontrados no momento da construção deste instrumento não captavam adequadamente essa complexidade. Deste modo, Messer e Harter (1986) construiram o perfil de auto-perceção para adultos procurando responder à necessidade de desenvolvimento de um instrumento psicométrico que refletisse adequadamente a complexidade do auto-conceito multidimensional do adulto. Baseando-se na própria conceptualização teórica do auto-conceito, o Adult Self-Perception Profile (Messer \& Harter, 1986) comporta uma abordagem multidimensional do auto-conceito que se reflete na conceção que os indivíduos, na maioria dos casos, não se vêem como igualmente competentes em todos os domínios. A autora incluiu no instrumento 11 domínios específicos e um de auto-conceito geral, a saber: sociabilidade, competência no trabalho, competência para cuidar dos outros, habilidades atléticas, aparência física, capacidade para sustentar os outros, moralidade, competência para a gestão das tarefas domésticas, competência nos relacionamentos íntimos, inteligência, sentido de humor e uma dimensão do auto-conceito global. A escala possui um total de 50 itens, sendo que cada uma das sub-escalas possui quatro itens, excetuando a escala referente ao auto-conceito global que é constituída por seis itens. A consistência interna das escalas varia entre .64 e .89. Relativamente ao modo como os itens são enunciados em cada sub-escala, metade dos itens estão enunciados de forma a que a primeira parte da afirmação reflita um elevado sentido de competência, estando a outra metade elaborada de forma oposta. Considerando o propósito deste estudo, recorremos apenas às escalas diretamente relacionadas com o objeto de estudo, competência no trabalho, competência para cuidar dos outros, competência para a gestão das tarefas domésticas e auto-conceito global.

\section{Procedimento}

A coleta de dados foi antecedida de consentimento livre e informado. Os participantes foram esclarecidosacerca da natureza voluntária da participação e do propósito do estudo, tendo sido também assegurada confidencialidade e o anonimato das respostas. Após permissão das respetivas instituições de ensino superior, os questionários foram coletivamente administrados no período disponibilizado para o efeito, pela autora do estudo assistido por três assistentes de investigação, duas psicólogas e um psicólogo. Noutros casos foram administrados individualmente. A duração média de preenchimento dos questionários foi de uma hora. Para o tratamento dos dados e análises estatísticas, foram utilizados os programas SPSS (15.0). 
Quadro 1. Médias e desvios padrão das variáveis em estudo.

\begin{tabular}{lcccc}
\hline & Estudantes & \multicolumn{2}{c}{ Trabalhadores } \\
\hline Fatores das Escalas & Média & D.P. & Média & D.P. \\
\hline ISPF2 - Independência emocional & 39.18 & 6.27 & 34.13 & 5.55 \\
\hline ISPF3 - Independência funcional & 26.09 & 4.87 & 28.00 & 5.27 \\
\hline AUTOPF1 - Auto-conceito global e de competência no trabalho & 29.26 & 6.72 & 26.94 & 5.78 \\
\hline AUTOPF2 - Competência para cuidar dos outros & 18.30 & 2.94 & 18.90 & 3.00 \\
\hline AUTOPF3 - Competência na gestão das tarefas domésticas & 10.44 & 2.72 & 10.93 & 2.69 \\
\hline IDENF2 - Identidade moratória e difusão & 52.64 & 6.29 & 55.43 & 6.69 \\
\hline
\end{tabular}

\section{Resultados}

Considerando os objetivos de estudo anteriormente enunciadas que na sua globalidade apontam para possíveis diferenças entre adultos emergentes de acordo com o estatuto ocupacional, num primeiro momento foi efetuada uma análise de diferenças de médias com recurso ao teste Manova. Esta revelou um efeito principal de acordo com o estatuto $(F(2,701)=9.435, p \leq 0.001)$. As diferenças significativas e as médias e os desvios padrões de cada grupo são apresentados no Quadro 1. No que se refere à independência, os estudantes apresentam uma maior independência emocional do que os trabalhadores $F(1,701)=-11.498, p \leq 0.001)$ enquanto que estes últimos apresentam uma maior independência funcional do que os estudantes $F(1,701)=4.790, p \leq 0.001)$.

$\mathrm{Em}$ relação à auto-perceção verifica-se que os estudantes apresentam um auto-conceito global e de competência no trabalho mais elevado do que os jovens trabalhadores $(F(1,701)=-4.340, p \leq 0.001)$, enquanto que os trabalhadores percecionam-se como maior competência para cuidar dos outros $F(1,701)=2.499, p \leq 0.013)$ e para gerir as tarefas domésticas do que os estudantes $F(1$, $701)=2.212, p \leq 0.028$ ). Nos estatutos de identidade os trabaIhadores apresentam-se mais em moratória e difusão do que os estudantes $(F(1,701)=5.614, p \leq 0.001)$.

\section{Discussão}

A independência emocional relativa às figuras parentais apresenta, no grupo de estudantes, valores significativamente mais elevados em comparação com a dos trabaIhadores, o que infirma parcialmente a nossa hipótese $(\mathrm{H} 3)$. Ora, a teoria da separação psicológica das figuras parentais defende que a autonomia emocional está associada a uma melhor capacidade de adaptação, em relação às exigências sociais, permitindo que o jovem se afirme ao nível do desempenho dos papéis de adulto. Sendo definida como uma relativa liberdade do jovem adulto em relação à necessidade excessiva de aprovação, proximidade e apoio emocional por parte dos pais, seria, de algum modo, de esperar que, a uma etapa desenvolvimental onde já se exerce um dos papéis de adulto (neste caso o papel profissional) estivesse associado um nível de autonomia emocional mais elevado, por comparação com a situação de estudante universitário. Contudo, tal não se verificou no presente estudo. Deste modo, torna-se importante refletir sobre as possíveis explicações para o fato dos trabalhadores se encontrarem menos independentes dos pais, do ponto de vista afectivo e emocional quando comparados com os estudantes. Duas hipóteses explicativas podem ser avançadas. Por um lado, e relembrando o que tem vindo a ser apontado por alguns autores, as alterações sociais, nomeadamente as dificuldades de encontrar emprego e os elevados custos para garantir uma residência autónoma, têm conduzido a uma maior dependência e permanência dos jovens em regimes de coabitação com os pais, quando terminam a sua formação universitária e mesmo por períodos que ultrapassam o início da atividade profissional (Andrade, 2010a; Arnett, 2000; Rossi, 1997).

Surgem, também, novas questões e opções em relação à vida adulta de que os adultos emergentes podem beneficiar se forem resolvidas no quadro de apoio emocional por parte dos pais. De fato, muitos adultos emergentes que já terminaram a sua formação universitária sentem falta de confiança nas suas próprias capacidades, não se julgam capazes de enfrentar o futuro com autonomia e, frequentemente, indicam que não se sentem suficientemente preparados para encarar os papéis de adulto (Andrade, 2010a; Andrade, 2010b; Mendonça, Andrade, \& Fontaine, 2009; Rossi, 1997). Estes afirmam, ainda, que o apoio emocional que recebem dos pais é fundamental para encararem as opções e ultrapassar os eventuais obstáculos que surgem no início da idade adulta (Cavalli, 1997; Rossi, 1997). Os estudos de Leondari e Kiosseoglou (2000) e Lee e Hughey (2001) encontraram níveis elevados de proximidade afetiva e emocional nas relações familiares, entre jovens adultos e os seus pais. Além disso, e na linha de Cavalli (1997), reportando-se aos jovens adultos profissionais que residem com os pais, parece que quanto mais autonomia instrumental os jovens sentem em relação à sua família, mais dependentes 
ao nível emocional se tornam da mesma, na medida em que têm mais capacidade para dar valor a este apoio que os pais podem dar em momentos de decisão, ou mesmo de instabilidade afetiva e profissional. De fato, os adultos emergentes que vivem com os pais não só estão satisfeitos com a sua situação como continuam a considerar os pais como a sua principal fonte de apoio emocional (Rossi, 1997). Com efeito, as próprias alterações no contexto da família e da relação pais-filhos, exercidas no sentido da redução de conflitos entre gerações, valorizam cada vez mais o apoio emocional entre pais e filhos (Cavalli, 1997).

Deste modo, parece-nos que uma das possíveis explicações para os resultados encontrados pode residir nesta relação entre o prolongamento da estadia em casa dos pais por parte dos adultos emergentes trabalhadores e o consequente apoio por parte destes, que poderá conduzir a uma valorização do apoio emocional para enfrentar a transição do ensino para o mercado de trabalho. Estes adultos emergentes trabalhadores estarão, assim, mais sensíveis à importância do apoio afetivo que é dado pelos pais, o que poderá justificar as diferenças em relação aos universitários. Por outro lado, a proximidade e necessidade de aprovação, por parte dos pais, no caso dos adultos emergentes universitários, pode, em determinados momentos, colidir com o desejo de independência e de exploração de diferentes oportunidades, que os jovens universitários querem assumir. Isto justificaria uma valorização da independência emocional para os estudantes. Uma vez terminada esta etapa da vida universitária, e uma vez assumido um dos papéis de adulto, a necessidade de afirmação da independência deixa de ser tão relevante dando mais ênfase à independência funcional como veremos mais adiante.

$\mathrm{Na}$ sequência dos argumentos expostos e para o contexto nacional, e tal como acontece noutros países, face ao risco e à incerteza no mundo do trabalho, o apoio dos pais às transições para a vida adulta, embora fundamental parece também dar origem também a uma certa dependência, nas situações em que os filhos permanecem até idade avançada na casa dos pais, num estatuto de "semi-dependência" que se reflete também ao nível emocional (Andrade, 2010a; Guerreiro \& Abrantes, 2004). Como evidencia Pappámikail (2004), nos jovens portugueses a convivência entre pais e os seus filhos adultos que exercem uma profissão é configurada por cenários de interdependência emocional, que se acentuam em situações de crise, ou seja, existe uma garantia de apoio emocional aos filhos para enfrentarem as situações mais difíceis da sua vida. Globalmente, parece-nos que os fatores de natureza social, nomeadamente para os adultos emergentes trabalhadores que vivem com os pais, configuram novas relações entre pais e filhos, que se transformam em interdependências e formas de apoio emocional, bastante relevantes para a transição para a idade adulta sobretudo no período de inserção no mercado de trabalho. No seu conjunto parece-nos que isto poderá contribuir para a explicação das diferenças encontradas entre os grupos.

O estatuto de identidade moratória está mais presente nos trabalhadores do que nos estudantes. Os resultados não permitem confirmar, parcialmente, a nossa hipótese $\mathrm{H} 1$. Ora, no quadro da adultez emergente de Arnett (2000), seria esperado que os estudantes, por se encontrarem num período de exploração das suas vidas pessoais e profissionais, pudessem apresentar níveis mais elevados no estatuto de moratória. Um dado que se torna relevante na discussão destes resultados está associado ao fato dos estatutos de identidade não serem fixos, mas pressuporem avanços e recuos desenvolvimentais. Assim, ao analisar os contextos de vida dos estudantes, pensamos que, mesmo que estes se questionem e explorem diferentes opções de vida, não necessitam de tomar decisões definitivas nem de assumir compromissos duradouros. Como alguns estudos demonstram, o contexto universitário implica liberdade para o desenvolvimento pessoal, sendo um período voltado para novas experiências, um período para "viver a vida", ou seja, sem grandes restrições ou responsabilidades ou compromissos embora os estudantes, pelas opções académicas que efectuaram, podem julgar já ter definido as suas opções de vida futura (Danielsen, Lorem, \& Kroger, 2000).

Se este período pressupõe o desenvolvimento de um projeto de vida adulta, a verdade é que, na maioria dos casos, o investimento neste projeto não toma automaticamente forma, quando se dá início ao exercício do papel profissional. A exploração continua a ser estimulada tanto pelas frequentes alterações na atividade profissional, como com a possibilidade de retorno ao sistema educativo para completar a formação julgada necessária, no âmbito de um projecto profissional e pessoal que se define progressivamente (Arnett, 2000). Isto poderá, então, refletir-se no predomínio de um estatuto de identidade moratória para esta fase da adultez emergente. Em nosso entender, uma das grandes diferenças entre os estudantes e os trabalhadores, é que estes últimos estão imersos num contexto de certa ambiguidade, que pode implicar uma necessidade de reflexão acerca de si mesmos e acerca do futuro e pôr novamente em questão opções anteriores, para poderem comprometer-se com decisões e opções de vida. Parece-nos que esta reflexão é orientada por um certo paradoxo entre o que se deseja, em termos de projetos de vida adulta, e o que poderá ser possível obter, face aos constrangimentos sociais reais. Parece, assim, que são mais os trabalhadores e menos os estudantes quem está a viver "verdadeiramente" a transição para a idade adulta, o que certamente implica um questionamento pessoal ativo, característico do estatuto de identidade moratória.

No auto-conceito global e competência no trabalho os trabalhadores apresentam valores inferiores aos estudantes, confirmando, deste modo, a nossa hipótese2. Vimos que os trabalhadores apresentam níveis superiores no estatuto de identidade moratória, o que está associado a uma fase intensa de reflexão e questionamento pessoal acerca das suas capacidades e das suas opções em relação à vida adulta. Este período de questionamento que os adultos emergentes trabalhadores atravessam pode estar intimamente associado a dúvidas quanto à sua competência, que se traduzem por valores mais baixos no auto-conceito, na medida em que as experiências reais de trabalho desenvolvem um maior sentido 
crítico dos jovens acerca de si próprios. Destaca-se, também que estas dúvidas englobam a componente da competência no trabalho com consequências evidentes. Conforme temos vindo a destacar o confronto direto, nos primeiros anos de inserção mercado de trabalho, com a realidade laboral, a par de algumas dificuldades ao nível da concretização de expetativas em relação ao trabalho e carreira, pode levar a que estes jovens tenham uma imagem pessoal da sua competência no trabalho inferior à dos estudantes, que estão ainda imersos num contexto em que qualquer expetativa é legítima, face à possibilidade de concretizarem uma atividade profissional. Consequentemente, a imagem de si próprio, ao nível profissional dos trabalhadores, estará mais sujeita a questionamento e a flutuações nesta fase de inserção no mercado de trabalho, do que no caso dos estudantes, o que pode justificar as diferenças significativas encontradas entre os estudantes e eles para este domínio.

Apesar do que se acabou de expor relativamente aos efeitos das dificuldades do mercado de trabalho e o modo como estas podem fazer decrescer as atitudes dos jovens trabalhadores em relação a este domínio parece-nos contudo que a inserção laboral, mesmo que não seja completamente conseguida pode promover a independência funcional destes adultos emergentes. De fato, um dos resultados obtidos e que não nos parece surpreendente reside no fato dos trabaIhadores obterem valores ao nível da independência funcional significativamente mais elevados do que os estudantes. Os resultados suportam parcialmente a hipótese $\mathrm{H} 3$.

$\mathrm{Na}$ nossa perspetiva os estudantes portugueses tendem a ser bastante dependentes do ponto de vista económico, residencial e mesmo nas suas práticas diárias em relação aos pais. Os trabalhadores, por via das necessidades com se deparam, de encontrar um emprego, tentarem economizar com vista a uma vida autónoma, ou serem capazes de gerir as suas prioridades de vida, ou mesmo pelo fato de já exercerem uma atividade profissional, tornam-se mais independentes do ponto de vista funcional em relação aos pais. Pensamos assim que estes resultados podem ser de fato um reflexo da etapa de vida que cada um dos grupos de jovens está a atravessar.

Os adultos emergentes estudantes apresentam valores significativamente menos elevados do que os adultos emergentes trabalhadores, na avaliação de competência para a gestão das tarefas domésticas e na avaliação de competência para cuidar dos outros. Estes resultados não permitem confirmar a nossa hipótese H2. Se o início do exercício do papel profissional se reveste de um conjunto de exigências em termos de disponibilidade de horários e de desgaste pessoal, a sensibilidade para a necessidade de exercer de tarefas domésticas e cuidar dos outros parece também aumentar. Apesar das primeiras tarefas serem, de fato, muitas vezes exigentes em termos de tempo, a execução de pequenas tarefas domésticas no seio da família de origem, poderá levar os trabalhadores a ter uma perspetiva mais otimista sobre a sua capacidade de gerir este tipo de tarefas.

Quanto à perceção de competência para cuidar dos outros, quando comparados com os estudantes, os trabalha- dores apresentam valores mais elevados. Para compreender estes resultados, é necessário ter em conta novamente a etapa do ciclo de vida que atravessam. Assim, e mesmo que o adiamento dos papéis familiares possa estar presente nos planos de vida dos jovens trabalhadores, o sentimento de competência para cuidar dos outros pode estar mais presente nos trabalhadores do que nos estudantes. Estes últimos estão mais centrados em si próprios e em tarefas desenvolvimentais, que passam por explorações no domínio vocacional eafetivo, estando, portanto, mais distantes de tarefas que envolvam o cuidado com os outros. Para além disto, tal como foi já destacado no estudo de Tang (1997) existe disponibilidade dos jovens adultos trabalhadores que residem com os pais para cuidar destes, sempre que necessário. No seu conjunto, parece-nos que estes fatos poderão contribuir para as diferenças encontradas entre grupos, em relação a estas variáveis.

Por último, gostaríamos de tecer um breve comentário sobre o fato de algumas das variáveis não permitirem diferenciar os grupos. Começando pelos estatutos de identidade verifica-se que não há diferenças nos grupos em relação aos estatutos de identidade vicariante e construída. De fato, estes resultados não confirmam as propostas da literatura que indicam que, à medida que se vai avançando ao longo do ciclo vital, a identidade construída tende a surgir e a identidade vicariante tende a estar presente sobretudo nos jovens mais novos. No nosso estudo parece, então, que a presença destes estatutos de identidade surge em ambos os grupos, o que poderá ser um indicador dos tais avanços e retrocessos na construção da identidade que são documentados por alguns autores.

\section{Considerações Finais}

Os resultados, embora de natureza exploratória, permitem contribuir para uma melhor compreensão do modo como, em dois grupos de adultos emergentes que se diferenciam pelo estatuto ocupacional, os contrutos psicológicos da identidade, o auto-conceito e autonomia apresentam diferenças. Deste modo, o exercício de uma atividade profissional parece destacar-se como uma dimensão relevante tanto para a construção da identidade como para o questionamento do auto-conceito e da própria autonomia.

Apesar do interesse de efetuar comparações entre adultos emergentes que ainda frequentam o ensino superior e aqueles que já o fizeram e estão agora no mercado de trabalho, os resultados obtidos devem ser lidos com precaução. Estudos futuros que envolvam o seguimento longitudinal destes grupos podem permitir avaliar, de forma mais precisa, o modo como a inserção no mercado de trabalho ou mesmo a transição do ensino superior para o mercado de trabalho exercem influência do modo como os adultos emergentes construem a sua identidade, auto-conceito e mesmo como vão progressivamente delineando processos de autonomia. Para além deste aspeto as características da amostra deste estudo também constituem uma limitação para a extrapola- 
ção destes resultados para outros grupos de adultos emergentes que, por exemplo, não frequentaram o ensino superior. A inclusão de uma amostra de maior dimensão e mais heterogénea e representativa da realidade adultos emergentes portugueses poderá permitir avaliar a consistência destes resultados, bem como o seu aprofundamento.

\section{Referências}

Adamson, L., \& Lyxell, B. (1996). Self-concept and questions of life: identity development during late adolescence. Journal of Adolescence, 19, 569-582.

Andrade, C. (2010a). Transição para a Idade Adulta: das Condições Sociais às Implicações Psicológicas. Análise Psicológica, XXVIII (2), 255-267.

Andrade, C. (2010b). Trabalho e Família na transição para a Idade Adulta. Porto: LivPsic.

Arnett, J. (2000). Emerging adulthood: A theory of development from the late teens through the twenties. American Psychologist, 55, 469-480.

Blos, P. (1979). Modifications in the classical psychoanalytical model of adolescence. Adolescent Psychiatry, 7, 6-25.

Cavalli, Alessandro (1997). "The delayed entry into adulthood: is it good or bad for society?". Em J.M. Pais \& L. Chrisholm (orgs.), Jovens em Mudança, Lisboa, Instituto de Ciências Sociais da Universidade de Lisboa.

Cole, D.A., Maxwell, S. E., Martin, J.M., Peeke, L.G., Seroczyynski, A.D., Tram, J.M., Hoffman, K. B., Ruiz., M.D., Jacquez, F., \& Maschman, T. (2001). The developmental of multiple domains of child and adolescent self-concept: a cohort sequential longitudinal design. Child Development, 72, 1723-1746.

Costa, M.E. (1991). Contextos sociais de vida e desenvolvimento da identidade. Lisboa: INIC.

Côté, J. (1996). Sociological perspectives on identity formation: The culture-identity link and identity capital. Journal of Adolescence, 19, 417-428.

Côté, J.E. \& Schwartz, S. J. (2002). Comparing psychological and sociological approaches to identity: identity status, identity capital, and the individualization process. Journal of Adolescence, 25, 571586 .

Danielsen, L., Lorem, A., \& Kroger, J. (2000).The impact of social context on the identity-formation process of Norwegian late adolescents. Youth and Society, 31, 332-362.

Dias, G.F. (1996). Tarefas desenvolvimentais e bem-estar psicológico dos jovens. Tese de doutorado não publicada, Faculdade de
Psicologia e de Ciências da Educação, Universidade do Porto, Portugal.

Guerreiro, M., \& Abrantes, P. (2004). Moving into adulthood in southern European country: Transitions in Portugal. Portuguese Journal of Social Science, 3, 191-209.

Harter, S. (1983). Developmental perspectives on self-system. Em E. M. Hetherington (Org.), Handbook of Child Psychology (pp. 275385). N. Y.: Wiley

Hoffman, J. A. (1984). Psychological separation of late adolescents for their parents. Journal of Counselling Psychology, 31, 170-178.

Lee, H. \& Hughey, K. F. (2001).The relationship of psychological separation and parental attachment to the career maturity of college freshmen from the intact families. Journal of Career Development, 27, 279-293.

Leondari, A., \& Kiosseoglou, G. (2000).The relationship of parental attachment and psychological separation to the psychological functioning of young adults. The Journal of Social Psychology, 140, 451-464.

Marcia, J. (1966). Development and validation of ego-identity status. Journal of Personality and Social Psychology, 3, 551-558

Marcia, J. (1986). Clinical implications of the identity status approach within psychosocial developmental theory. Cadernos de Consulta Psicológica, 2, 23-34.

Matos, P.M., Barbosa, S., Almeida, H.M., \& Costa, M.E. (1999). Parental attachment and identity in Portuguese late adolescents. Journal of Adolescence, 22, 805-818.

Mendonça, M., Andrade, C., \& Fontaine, A.M. (2009). Transição para a idade adulta e adultez emergente: adaptação do Questionário de Marcadores da Adultez junto de jovens Portugueses. Psychologica, 51, 147-168.

Messer, B. \& Harter, S. (1986). Manual for the Adult Self Perception Profile Dever, CO: University of Denver.

Pappámikail, L. (2004). Relações intergeracionais, apoio familiar e transições juvenis para a vida adulta em Portugal. Sociologia, Problemas e Práticas, 46, 91-116.

Rosenberg, F., \& Simmons, R. G. (1975). Sex differences in the selfconcept in adolescence. Sex Roles, 1, 147-159.

Rossi, G. (1997). The nestlings - Why young adults stay at home longer: The Italian case. Journal of Family Issues, 18, 627-644.

Shavelson, R. J., Hubner, J. J., \& Stanton, G.C. (1976). Self-Concept: validation of construct interpretations. Review of Educational Research, 46, 407-411. 
Tang, S. (1997). The timing of home leaving: a comparison of early, on-time and late home leavers. Journal of Youth and Adolescence, 26, 13-23.

Tanner, J. (2006). Recentering during emerging adulthood: A critical turning point in life span human development. Em J. Arnett \& J. Tanner (Orgs.), Emerging adults in America: Coming of the Age in the 21st century (pp. 21-55). Washinghton: American Psychological Association.
Yount, K. R. (1986). A theory of produtive activity: the relationships among self-concept, gender, sex roles stereotypes, and workemergent traits. Psychology of Women Quartely, 10, 63-88.

Recebido em: 09/12/2014

Reformulado em: 14/06/2015

Aprovado em: 04/09/2015

\section{Sobre a autora}

Cláudia Andrade (mcandrade@esec.pt)

Doutoramento e Pós-Doutoramento em Psicologia

Profa. Adjunta da Escola Superior de Educação, Politécnico de Coimbra Membro do Centro de Psicologia da Universidade do Porto 